\title{
Correction to: Microstructural Characteristics of Oxide Layer Growth on Tin Whisker and Finish Surface
}

\section{Kyung-Seob Kim ${ }^{1}$. Jong-Chang Woo ${ }^{2}$}

Published online: 20 September 2019

(c) The Korean Institute of Electrical and Electronic Material Engineers 2019

\section{Correction to: \\ Transactions on Electrical and Electronic Materials https://doi.org/10.1007/s42341-019-00125-7}

In the original publication of the article the sentence in the conclusions section that reads as "Both str crystalline and amorphous structures of $\mathrm{SnO}_{2}$ were observed" should read as "Both crystalline and amorphous structures of $\mathrm{SnO}_{2}$ were observed".
Errors have subsequently been identified in the original publication, and the following correction should be noted:

In the original publication of this article, the Figures 1, $4,5 \mathrm{a}, 5 \mathrm{~b}$ and $7 \mathrm{a}$ were published incorrectly. The corrected figures are given in this correction.

The original article can be found online at https://doi.org/10.1007/ s42341-019-00125-7.

Jong-Chang Woo

wjch97@ddu.ac.kr

1 Department of Semiconductor System, Yeoju Institute of Technology, Yeoju 12652, Republic of Korea

2 Department of Semiconductor and Automation, Daeduk University, Daejeon 34111, Republic of Korea 

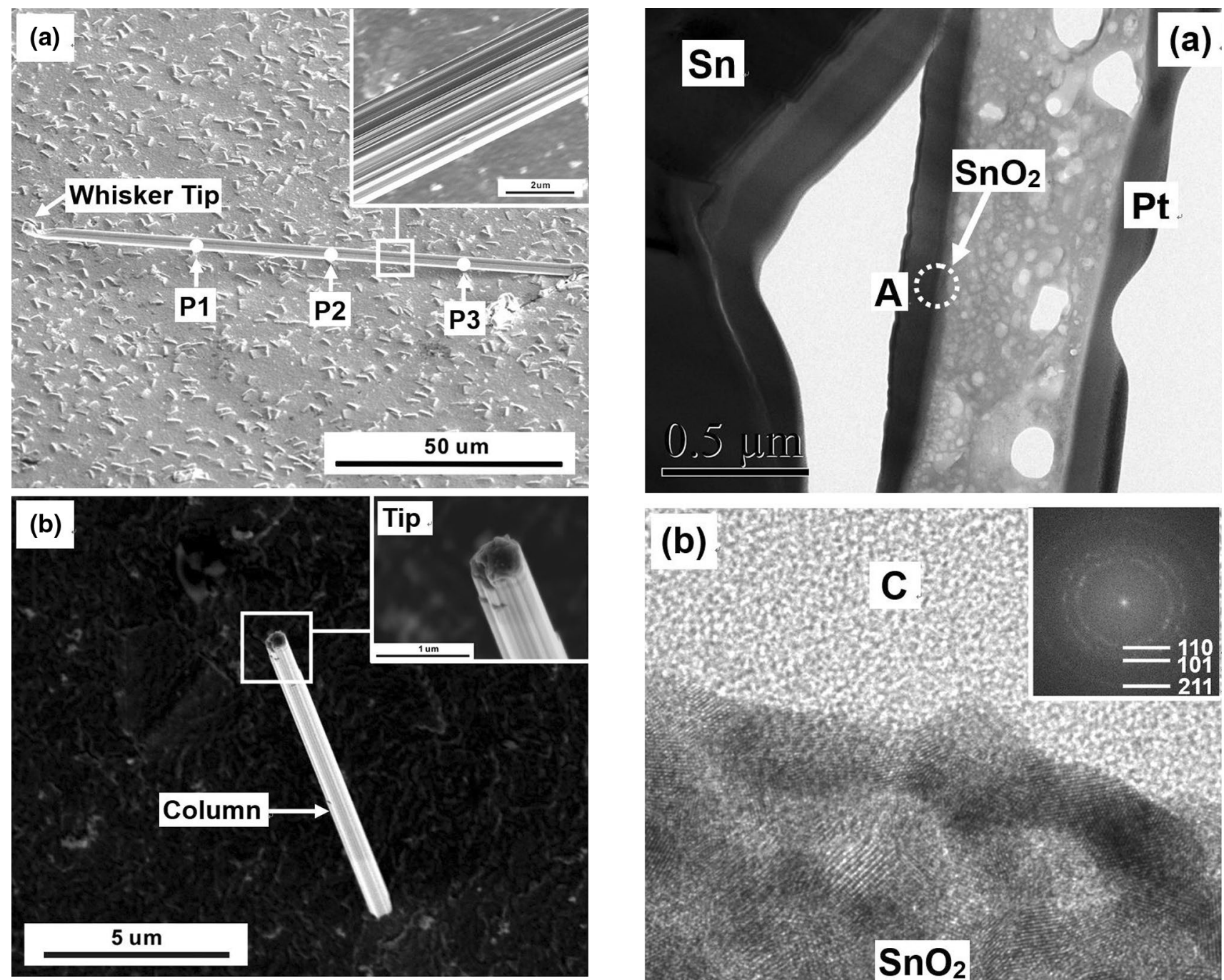

Fig. 1 FE-SEM images of whisker grown morphology on the pure Sn-plated $\mathrm{Cu}$. a After storage at room temperature for 20 years. b After storage at $55^{\circ} \mathrm{C}$ for 16 months

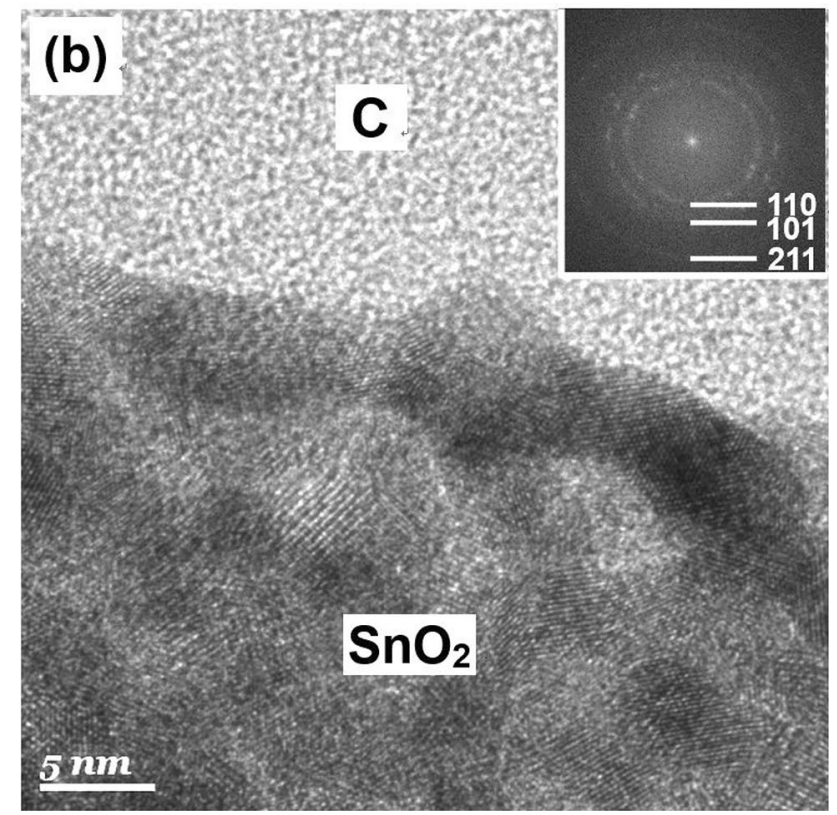

Fig. 4 The showing of the Pt coating interface at the surface of the $\mathrm{Sn}$ whisker after exposure at $55{ }^{\circ} \mathrm{C} / 85 \% \mathrm{RH}$ for 2 months. a Low magnification TEM image showing of the Sn oxide layer formed on the Sn whisker, $\mathbf{b}$ HR-TEM image and EDP obtained from circled area 'A' in Fig. 3a 
Fig. 5 Bright-field and HRTEM image showing the Sn oxide layer formed on the surface after stored at room temperature for 20 years. a A layer of $13.5-20.0 \mathrm{~nm} \mathrm{SnO}_{2}$ film on the surface of the Sn finish. Top left figure shows the close-up image of Fig. 4a. b The interface at the $\mathrm{C}$ coating and crystalline $\mathrm{Sn}$ whisker. The interface appears to be incoherent. c EELS spectra obtained from positions $1-5$ shown in Fig. 4b
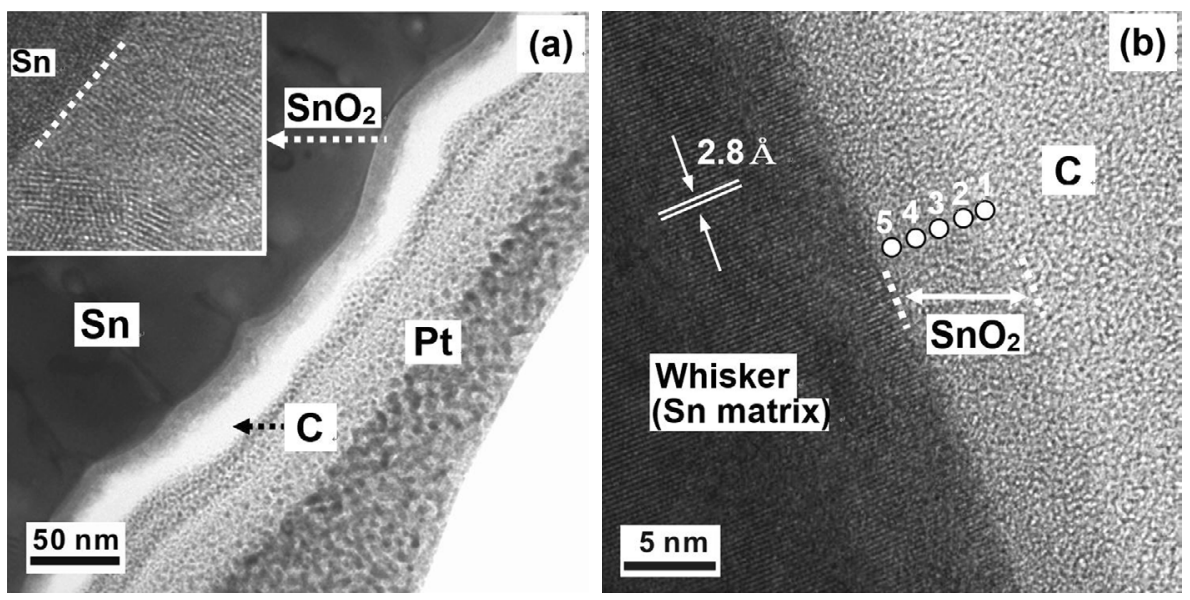

(c)

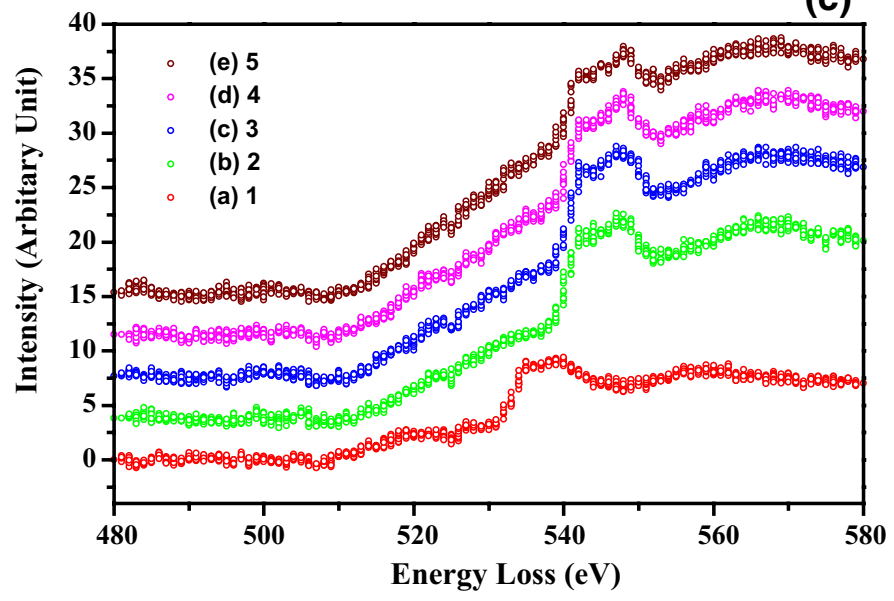




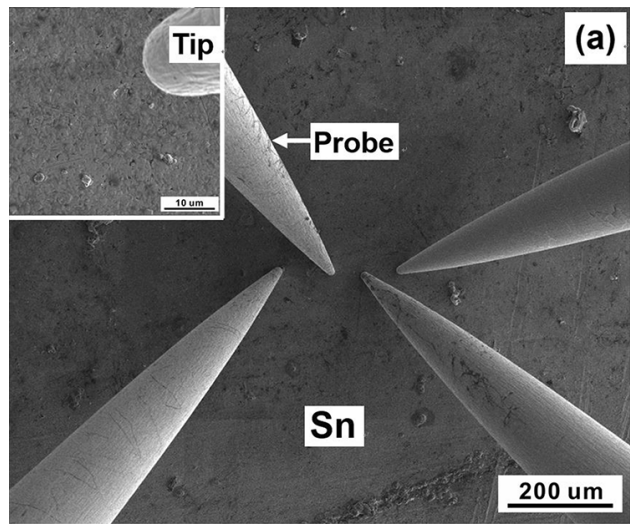

Publisher's Note Springer Nature remains neutral with regard to jurisdictional claims in published maps and institutional affiliations.

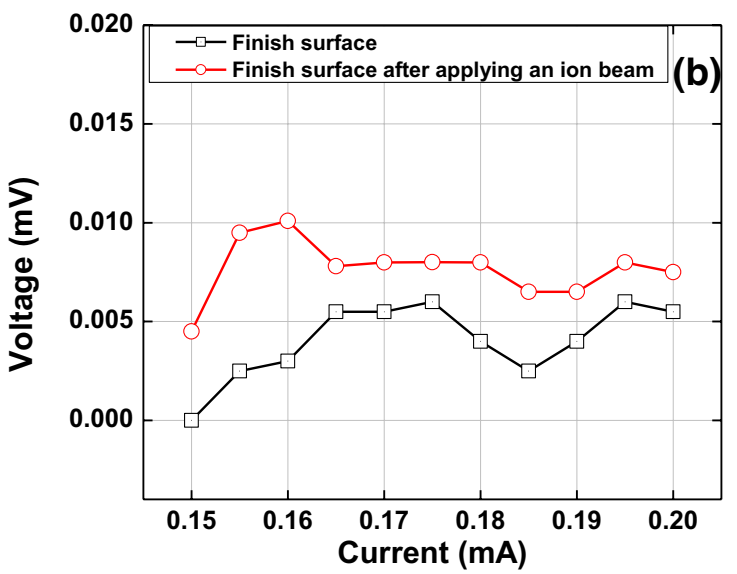

Fig. 7 a A direct contact image of Sn finish and four point nanoprobe manipulator. b I-V curve obtained from the direct contact measurement 